\title{
Pengaruh Front Top Roller Terhadap Ketidakrataan Benang Acrylic $100 \%$ pada Mesin Ring Spinning Merk Fukushima.
}

\author{
Giyanto $^{1)}$ Sutresna Juhara $^{2^{*}}$ dan Agus Tunjiral ${ }^{3 *}$ \\ Jurusan Teknik Industri, Fakultas Teknik, Universitas Islam Syekh Yusuf, Jl. Mulana Yusuf No.10 \\ Tangerang Banten 15118, Indonesia \\ 1) gianto wonri@ymail.com \\ ${ }^{2)}$ sjuhara@unis.ac.id \\ 3) tunjiral@gmail.com
}

\begin{abstract}
Abstrak. Salah satu kendala pada proses pembuatan kain adalah rendahnya efisiensi produksi. Penyebab rendahnya efisiensi produksi adalah karena benang sering putus. Putus benang terjadi pada bagian benang yang lemah, dan bagian yang lemah ini terjadi pada benang yang tipis. Untuk itulah perlu optimasi proses spinning terhadap peningkatan kerataan benang. Penelitian dilakukan di mesin spinning dengan menggunakan rancangan acak kelompok dengan tiga kali ulangan. Faktor-faktor yang diteliti meliputi tekanan front top roller yang terdiri dari tekanan 10 daN, 12 daN, 14 daN dan Diameter front top roller yang terdiri dari $28,0 \mathrm{~mm}, 28,5 \mathrm{~mm}, 29,0 \mathrm{~mm}$. Analisa data yang dipakai untuk menganalisa Analisis of variance (Anava). Karena ketidakrataan benang yang diharapkan adalah serendah mungkin, maka kriteria yang dipakai adalah semakin kecil semakin baik. Hasil eksperimen menunjukkan bahwa dengan memakai setting optimal yaitu tekanan front top roller 10 daN, dan Diameter front top29,0 mm menghasilkan nilai ketidakrataan benang yang paling baik yaitu sebesar 8,78.
\end{abstract}

Kata kunci: ketidakrataan benang, anova dua arah, proses spinning

Abstract. One of the problems of fabric manufacturing process is low production efficiency. Cause low production efficiency because the yarn often breakeages. Breaking of the yarn occurs on the weak part of yarn, and the weak part is present on the thin of the yarn. For that need to optimize the spinning process to improve evenness of the yarn. Research was conducted in a ring spinning machine using a randomized block design with tree repetitions. Factor-factor studied include front top roller pressure consisting of 10 daN, 12 daN, 14 daN pressure, and front top roller diameters consisting 28,0 mm, 28,5 mm, 29,0 mm. For analyze data using analisys of variance (Anova). Because the unevenness of the expected yarn low is possible, then the criterion used is the smaller the better. The result of experiment show that by using optimal setting of front top roller pressure $10 \mathrm{daN}$, and front top roller $29,0 \mathrm{~mm}$ resulting in better yarn unevenness that is 8,78 .

Keywords: yarn unevenness, 2-way anova, spinning process

\section{Pendahuluan}

Top roller adalah salah satu peralatan yang terdapat pada mesin ring spinning dan berpasangan dengan bottom roller yang merupakan pasangan rol peregang. Top roller terbuat dari besi yang bagian luarnya dilapisi dengan karet sintetis agar dapat memberi jepitan yang lebih baik, sedangkan bottom roller terbuat dari baja yang dikeraskan pada seluruh permukaannya dan beralur halus pada bagian tempat jalannya serat untuk mendapatkan jepitan yang lebih sempurna. Pada mesin ring spinning terdapat tiga pasang rol peregang yaitu rol peregang depan, tengah dan belakang. Masingmasing rol peregang terdiri dari rol atas (top roller) dan rol bawah (bottom roller), dimana kecepatannya makin kedepan makin cepat. Fungsi dari pasangan rol peregang tersebut adalah untuk terjadinya proses penarikan (drafting) sehingga diperoleh ukuran benang yang diinginkan. Proses drafting terjadi karena kecepatan rol depan/rol penarik lebih cepat dari rol belakang/ rol yang ditarik. Gambar daerah penarikan (drafting zones) seperti pada Gambar 1. 


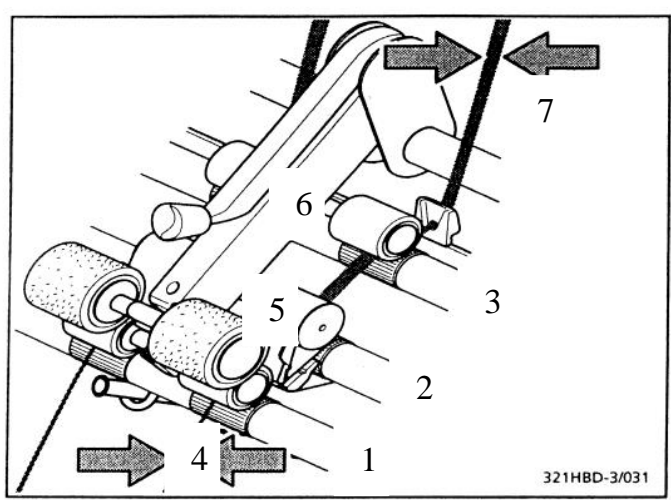

Gambar 1. Drafting zone Mesin Ring Spinning Keterangan gambar

1. Front bottom roller

2. Middle bottom roller

3. back Bottom roller

4. Benang yang dihasilkan

5. Top roller

6. Weighting arm/pemberat

7. Bahan baku benang yang diproses

Dengan adanya proses penarikan ini akan terjadi pengecilan berat persatuan panjang serta benang yang dihasilkan ketidakrataanya meningkat. Ketidakrataan benang adalah ukuran yang menunjukkan penyimpangan berat per satuan panjang terhadap nilai rata-ratanya. Nilai ketidakrataan benang yang semakin tinggi berarti benang kurang rata atau kurang baik. Proses drafting yang sempurna salah satunya tergantung dari tekanan dan diameter top roller. Pembebanan adalah untuk mendapatkan tekanan sepanjang titik jepit dan mengontrol serta mencegah terjadinya slip pada saat peregangan berlangsung. Pemberian pembebanan yang terlalu tinggi dapat menyebabkan jepitan serat terlalu keras sehingga banyak serat putus, begitu sebaliknya pemebanan terlalu rendah penjepitan seratnya kurang sempurna sehingga benang yang dihasilkan kurang rata. Diameter top roller yang terlalu kecil luas titik jepitnya akan kecil pula sehingga pada saat proses penarikan serat penjepitannya kurang sempurna sehingga benang yang dihasilkan kurang rata. Sehubungan dengan uraian diatas, maka peneliti ingin mengetahui pengaruh variasi tekanan dan diameter front top roller terhadap ketidakrataan benang.

\section{Rumusan Masalah}

Rumusan masalah dalam penelitian ini adalah bagaimana memperbaiki ketidakrataan benang yang dihasilkan dengan merancang kombinasi setting melalui eksperimen. Untuk itu dilakukan serangkaian tahapan percobaan yang bertujuan untuk mengidentifikasi faktor-faktor apa saja yang berpengaruh terhadap ketidakrataan benang, mengidentifikasi level setting mesin spinning yang digunakan dalam proses pembuatan benang sehingga didapatkan setting yang optimal guna meperbaiki ketidakrataan benang.

\section{Bahan dan Metode:}

1. Variabel bebas atau faktor terkendali.

Bentuk penelitian adalah eksperimental, dengan rancangan percobaan berbentuk faktorial L1 $x L 2=3 \times 3$. Dimana :

L1 = Faktor tekanan front top roller

L2 = Faktor diameter front top roller

$3=$ Jumlah variasi tekanan front top roller, terdiri dari 10 daN, 12 daN dan 14 daN

$3=$ Jumlah variasi diameter front top roller, terdiri dari 28,0 mm, 28,5 $\mathrm{mm}$ dan 29,0 $\mathrm{mm}$.

Masing-masing variasi dari kedua faktor tersebut dibuat pola kombinasi langsung di mesin ring spinning sehingga membentuk pola kombinasi perlakuan yang dapat dilihat pada Tabel 1.

Tabel 1. Pola Kombinasi Perlakuan Faktor Tekanan Front Top Roller Dengan Diameter Front Top Roller Dengan 3 Ulangan.

\begin{tabular}{cccc}
\hline $\begin{array}{c}\text { Diameter } \\
\text { front top } \\
\text { roller }(\mathrm{mm})\end{array}$ & $\begin{array}{c}\text { Tekanan front top roller } \\
\text { (daN) }\end{array}$ & \\
\cline { 2 - 4 } & 10 & 12 & 14 \\
\hline 28,0 & 3 & 3 & 3 \\
\hline 28,5 & 3 & 3 & 3 \\
\hline 29,0 & 3 & 3 & 3 \\
\hline
\end{tabular}

\section{Variabel Respon.}

Variabel respon atau karakteristik kualitas yang menjadi perbaikan dalam penelitian adalah ketidakrataan benang.

III. Hasil dan Pembahasan

1. Pengujian Ketidakrataan Benang $(\mu \%)$.

Dalam penelitian ini setelah mesin disetting sesuai variasi penelitian, kemudian benang di uji ketidakrataan benangnya dengan alat Uster Eveness tester yang dapat dilihat pada Tabel 2.

Tabel 2. Data Hasil Ketidakrataan Benang Acrylic $100 \%$ Di Mesin Ring Spinning Pengaruh Tekanan Front Top Roller Dengan Diameter Front Top Roller. 


\begin{tabular}{|c|c|c|c|}
\hline \multirow{2}{*}{$\begin{array}{l}\text { Diameter } \\
\text { front top } \\
\text { roller }(\mathrm{mm})\end{array}$} & \multicolumn{3}{|c|}{$\begin{array}{l}\text { Tekanan front top roller } \\
\text { (daN) }\end{array}$} \\
\hline & 10 & 12 & 14 \\
\hline \multirow[t]{3}{*}{28,0} & 8,96 & 8,77 & 8,90 \\
\hline & 8,76 & 8,99 & 8,75 \\
\hline & 8,88 & 8,76 & 8,69 \\
\hline \multirow[t]{3}{*}{28,5} & 9,05 & 8,79 & 8,76 \\
\hline & 9,15 & 8,76 & 8,99 \\
\hline & 8,99 & 8,96 & 8,85 \\
\hline \multirow[t]{3}{*}{29,0} & 9,21 & 9,12 & 9,12 \\
\hline & 9,12 & 9,11 & 9,05 \\
\hline & 9,22 & 9,09 & 9,16 \\
\hline
\end{tabular}

\section{Analisa Statistik Hasil Pengujian}

Untuk mengetahui seberapa besar pengaruh tekanan dan diameter front top roller terhadap ketidakrataan benang, maka dilakukan analisa statistik metode hipotesis. Pengujian hipotesis dilakukan dengan teknik analisis statistik Anova dua arah dengan interaksi. Secara umum tabel observasi penelitian seperti pada Tabel 3 .

Tabel 3. Tabel Observasi Penelitian

\begin{tabular}{|c|c|c|c|c|c|}
\hline & 1 & $2 \ldots \ldots \ldots$ & C & Total & Mean \\
\hline \multirow[t]{6}{*}{1} & $\mathrm{X}_{111}$ & $\mathrm{X}_{121 \ldots . .}$ & $\mathrm{Xt}_{\mathrm{c} 1}$ & $\mathrm{~T}_{1 . .}$ & $\mathrm{X}_{1 . .}$ \\
\hline & $\mathrm{X}_{112}$ & $\mathrm{X}_{122} \ldots \ldots$ & $\mathrm{Xt}_{\mathrm{c} 2}$ & & \\
\hline & $\mathrm{X}_{113}$ & $\mathrm{X}_{123} \ldots . .$. & $\mathrm{Xt}_{\mathrm{c} 3}$ & & \\
\hline & - & & . & & \\
\hline & . & . & . & & \\
\hline & $\mathrm{X}_{11 \mathrm{n}}$ & $X_{12 n} \ldots .$. & $\mathrm{Xt}_{\mathrm{cn}}$ & & \\
\hline \multirow[t]{6}{*}{2} & $\mathrm{X}_{211}$ & $\mathrm{X}_{221} \ldots \ldots$ & $\mathrm{Xt}_{\mathrm{c} 1}$ & $\mathrm{~T}_{2 . .}$ & $\mathrm{X}_{2 . .}$ \\
\hline & $X_{212}$ & $\mathrm{X}_{222} \ldots \ldots .$. & $\mathrm{Xt}_{\mathrm{c} 2}$ & & \\
\hline & $X_{213}$ & $\mathrm{X}_{223}$ & $\mathrm{Xt}_{\mathrm{c} 3}$ & & \\
\hline & $\cdot$ & $\cdot$ & $\cdot$ & & \\
\hline & - & . & . & & \\
\hline & $X_{21 n}$ & $X_{22 n} \ldots \ldots$ & $\mathrm{Xt}_{\mathrm{cn}}$ & & \\
\hline \multirow[t]{6}{*}{$\mathrm{r}$} & $X_{\mathrm{r} 11}$ & $\mathrm{X}_{\mathrm{r} 21} \ldots \ldots$ & $\mathrm{Xt}_{\mathrm{cl}}$ & $\mathrm{T}_{\mathrm{r} \cdot \cdot}$ & $X_{\mathrm{r} .}$. \\
\hline & $X_{\mathrm{r} 12}$ & $\mathrm{X}_{\mathrm{r} 22} \ldots \ldots$ & $\mathrm{Xt}_{\mathrm{c} 2}$ & & \\
\hline & $\mathrm{X}_{\mathrm{r} 13}$ & $\mathrm{X}_{\mathrm{r} 23} \ldots \ldots$ & $\mathrm{Xt}_{\mathrm{c} 3}$ & & \\
\hline & $\cdot$ & . & · & & \\
\hline & . & $\cdot$ & - & & \\
\hline & $X_{21 n}$ & $X_{22 n} \ldots \ldots$ & $\mathrm{Xt}_{\mathrm{cn}}$ & & \\
\hline Total & T.1. & T.2. & $\ldots$. & T... & X... \\
\hline \multirow[t]{3}{*}{ Mean } & T.C. & & & & \\
\hline & X.1. & X.2. & $\ldots .$. & & \\
\hline & X.C. & & & & \\
\hline
\end{tabular}

Model Matematis.

$\mathrm{Xijk}=\mu \mathrm{ij}+\varepsilon \mathrm{ijk}$ $\varepsilon \mathrm{ijk}=$ Mengukur deviasi dari pengamatan $\mathrm{X}$ ijk pada tiap-tiap sel yang ke ij dari Mean populasi $\mu \mathrm{ij}$.

$\mu \mathrm{ij}=\mu+\alpha \mathrm{i}+\beta \mathrm{j}+(\alpha \beta) \mathrm{ij}$

$\mu \quad=$ Nilai mean dari seluruh populasi pengamatan yang ada

$\alpha \mathrm{i}=$ efek dari pengaruh baris

$B j=$ efek dari pengaruh kolom

$(\alpha \beta) \mathrm{ij}=$ efek pengaruh interaksi yang diperoleh dari efek baris dan efek kolom.

Hipotesis yang diambil adalah sbb :

1. $\mathrm{H}_{0}=\alpha 1=\alpha 2=\ldots \ldots$ ar $=0$

$\mathrm{H}_{\mathrm{A}}=$ paling sedikit satu diantara $\alpha \mathrm{i} \neq 0$

2. $\mathrm{H}_{0}=\beta 1=\beta 2=\ldots . . \mathrm{c}=0$

$\mathrm{H}_{\mathrm{A}}=$ paling sedikit satu diantara $B \mathrm{j} \neq 0$

3. $\mathrm{H}_{0}=(\alpha \beta)_{11}=(\alpha \beta)_{12}=\ldots . .(\alpha \beta) \mathrm{rc}=0$

$\mathrm{H}_{\mathrm{A}}=$ paling sedikit satu diantara $(\alpha \beta) \mathrm{ij} \neq 0$

\section{Hasil Penelitian}

Data yang diperoleh dari hasil pengujian ketidakrataan benang pada Tabel 2. Kemudian untuk mengetahui apakah ada pengaruh perbedaan antara kombinasi perlakuan terhadap ketidakrataan benang akan dianalisa dengan anova sebagai berikut:

Tabel 4. Data Jumlah Ketidakrataan Benang Acrylic $100 \%$.

\begin{tabular}{ccccc}
\hline $\begin{array}{c}\text { Diameter } \\
\text { front top } \\
\text { roller } \\
\text { (mm) }\end{array}$ & $\begin{array}{c}\text { Tekanan front top } \\
\text { roller (daN) }\end{array}$ & Total \\
\cline { 2 - 4 } & 10 & 12 & 14 & \\
\hline 28,0 & 26,6 & 26,5 & 26,3 & 79,4 \\
& 0 & 2 & 4 & 6 \\
\hline 28,5 & 27,1 & 26,5 & 26,6 & 80,3 \\
& 9 & 1 & 0 & 0 \\
\hline 29,0 & 27,5 & 27,3 & 27,3 & 82,2 \\
& 5 & 2 & 3 & 0 \\
\hline Total & 81,3 & 80,3 & 80,2 & 241, \\
& 4 & 5 & 7 & 96 \\
\hline
\end{tabular}

Tabel 5. Rata-Rata Ketidakrataan Benang Acrylic $100 \%$.

\begin{tabular}{|c|c|c|c|c|}
\hline \multirow{2}{*}{$\begin{array}{l}\text { Diameter } \\
\text { front top } \\
\text { roller } \\
(\mathrm{mm})\end{array}$} & \multicolumn{3}{|c|}{$\begin{array}{l}\text { Tekanan front top } \\
\text { roller (daN) }\end{array}$} & \multirow[t]{2}{*}{$\begin{array}{l}\text { Rata- } \\
\text { rata }\end{array}$} \\
\hline & 10 & 12 & 14 & \\
\hline 28,0 & 8,87 & 8,84 & 8,78 & $\mathbf{8 , 8 3}$ \\
\hline
\end{tabular}




\begin{tabular}{ccccc}
\hline 28,5 & 9,06 & 8,34 & 8,87 & 8,92 \\
\hline 29,0 & 9,18 & 9,11 & 9,11 & 9,13 \\
\hline Rata-rata & 9,04 & 8,93 & $\mathbf{8 , 9 2}$ & \\
\hline
\end{tabular}

4. Perhitungan Analisis Varians

a. Jumlah Kuadrat Total (JKT)

$$
\begin{aligned}
J K T= & \sum_{i=1}^{k} \sum_{j=1}^{n} x_{i j}^{2}-\frac{T^{2} \ldots}{b \cdot k \cdot n} \\
J K T= & 8,90^{2}+8,75^{2}+\ldots .+9,22^{2}-\frac{241,966^{2}}{27} \\
& =2169,025-2168,320=0,705
\end{aligned}
$$

b. Jumlah kuadrat baris (JKB)

$$
\begin{aligned}
J K B & =\frac{\sum_{i=1}^{k} T_{i}^{2}}{k \cdot n}-\frac{T^{2} \ldots}{b \cdot k \cdot n} \\
J K B & =\frac{82,20^{2}+80,30^{2}+79,46^{2}}{9}-\frac{241,96^{2}}{27} \\
& =2168,758-2168,320=0,438
\end{aligned}
$$

c. Jumlah kuadrat kolom (JKK)

$$
\begin{aligned}
J K K & =\frac{\sum_{i=1}^{k} T^{2} \cdot j}{b \cdot n}-\frac{T^{2} \ldots}{b \cdot k \cdot n} \\
J K K & =\frac{80,27^{2}+80,35^{2}+81,34^{2}}{9}-\frac{241,96^{2}}{27} \\
& =2169,399-2168,320=0,079
\end{aligned}
$$

d. Jumlah kuadrat interaksi (JKI)

$$
J K I=\frac{\sum_{i=1}^{b} \sum_{j=1}^{k} T_{i j}^{2}}{b \cdot n}-\frac{\sum_{i=1}^{b} T_{i}^{2}}{k \cdot n}-\frac{\sum_{j=1}^{k} T^{2} \cdot j}{b \cdot n}=\frac{T^{2}}{b \cdot k \cdot n}
$$

$\mathrm{JKI}=2168,872-2168,753-2168,399+2168,320$

$$
=0,035
$$

\section{e. Jumlah kuadrat error (JKE)}

$$
J K E=J K T-J K B-J K K-J K I
$$

\begin{tabular}{|c|c|c|c|c|c|}
\hline $\begin{array}{l}\text { Sumber } \\
\text { Varian }\end{array}$ & $\begin{array}{c}\text { Jumlah } \\
\text { Kuadrat } \\
\text { (JK) }\end{array}$ & $\begin{array}{c}\text { Dera } \\
\text {-jat } \\
\text { beba } \\
\text { s } \\
\text { (db) }\end{array}$ & $\begin{array}{c}\text { Kuad- } \\
\text { rat } \\
\text { Rerata }\end{array}$ & $F_{\text {hitung }}$ & Tabel \\
\hline
\end{tabular}

$J K E=0,705-0,438-0,079-0,035=0,153$

\section{f. Taraf nyata $(\alpha)$ dengan $F$ Tabel}

Untuk baris: $v_{1}=b-1$ dan $v_{2}=k b(n-1)$

Untuk kolom: $v_{1}=k-1 \mathrm{dan}$

$v_{2}=k b(n-1)$

Untuk interaksi $: v_{1}=(k-1)(b-1)$ dan

$$
v_{2}=k b(n-1)
$$

Hasil perhitungan selengkapnya untuk anova dua arah dengan interaksi ditunjukkan pada Tabel 5.

Tabel 6. Anova Dua Arah Dengan Interaksi

\begin{tabular}{llllrc}
\hline $\begin{array}{l}\text { Rata- } \\
\text { rata } \\
\text { baris }\end{array}$ & 0,438 & 2 & 0,2190 & 25,76 & 3,5 \\
5 & 5 \\
\hline $\begin{array}{l}\text { Rata- } \\
\text { rata } \\
\text { kolom }\end{array}$ & 0,079 & 2 & 0,0395 & 4,647 & $\begin{array}{c}3,5 \\
5\end{array}$ \\
\hline $\begin{array}{l}\text { Interaks } \\
\mathrm{i}\end{array}$ & 0,035 & 4 & 0,0087 & 1,024 & $\begin{array}{c}2,9 \\
3\end{array}$ \\
\hline Error & 0,153 & 18 & 0,0085 & & \\
\hline Total & & 26 & & & \\
\hline
\end{tabular}

Berdasarkan Tabel 5 didapatkan bahwa :

a. Untuk ketidakrataan benang dengan variasi tekanan front top roller $\mathrm{F}_{\text {hitung }}>\mathrm{F}_{\text {tabel }}$, ini menunjukkan bahwa $\mathrm{Ho}_{\mathrm{A}}$ ditolak sehingga dapat disimpulkan bahwa terdapat perbedaan pengaruh yang signifikan antara tekanan front top roller terhadap ketidakrataan benang.

b. Untuk ketidakrataan benang dengan variasi diameter front top roller $\mathrm{F}_{\text {hitung }}>\mathrm{F}_{\text {tabel }}$, ini menunjukkan bahwa HoA ditolak sehingga dapat disimpulkan bahwa terdapat perbedaan pengaruh yang signifikan antara diameter front top roller terhadap ketidakrataan benang.

c. Untuk ketidakrataan benang dengan variasi interaksi tekanan dengan diameter front top roller $\mathrm{F}_{\text {hitung }}<\mathrm{F}_{\text {tabel}}$, ini menunjukkan bahwa HoA diterima sehingga dapat disimpulkan bahwa tidak terdapat adanya interaksi antara tekanan front top roller dengan diameter front top roller terhadap ketidakrataan benang.

\section{Pembahasan}

a. Faktor Baris (Tekanan Front Top Roller)

Berdasarkan hasil pengujian analisis ragam bahwa tekanan front top roller memberi pengaruh yang signifikan terhadap ketidakrataan benang. Dimana grafik hubungan antara tekanan front op roller dengan ketidakrataan benang seperti terlihat pada Gambar 2. 


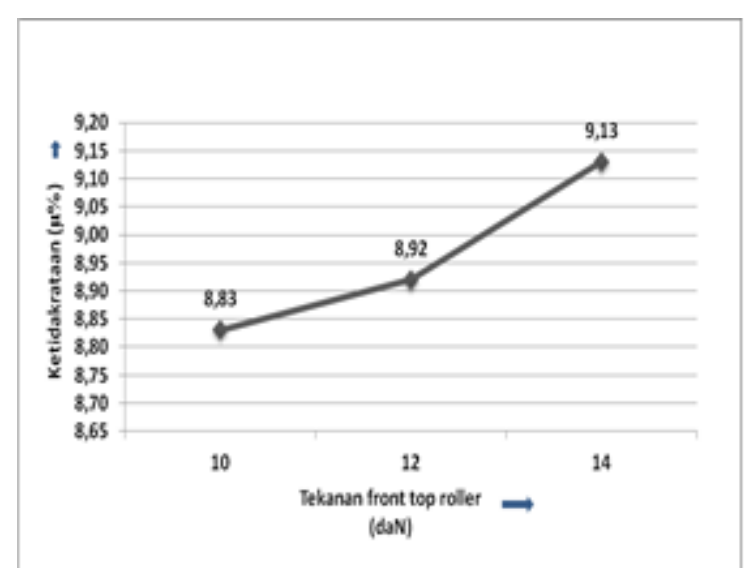

Gambar 2. Grafik Hubungan Tekanan Front Top Roller Dengan Ketidakrataan Benang.

Dari grafik diatas terlihat bahwa tekanan front top roller makin tinggi ketidakrataan benang semakin tinggi pula (kerataan benangnya kurang bagus). Hal ini disebabkan pada tekanan $14 \mathrm{daN}$ serat mendapat beban yang lebih tinggi sehingga pada saat terjadi proses drafting serat banyak yang putus sehingga menyebabkan ketidakrataan benangnya meningkat (kurang bagus). Ketidakrataan benang yang bagus adalah pada tekanan 10 daN dengan menghasilkan nilai ketidakrataan benang sebesar 8,83 .

\section{b. Faktor Kolom (Diameter Front Top Roller)}

Berdasarkan hasil pengujian analisis ragam bahwa diameter front top roller memberi pengaruh yang signifikan terhadap ketidakrataan benang. Dimana grafik hubungan antara diameter front top roller dengan ketidakrataan benang seperti terlihat pada Gambar 3 .

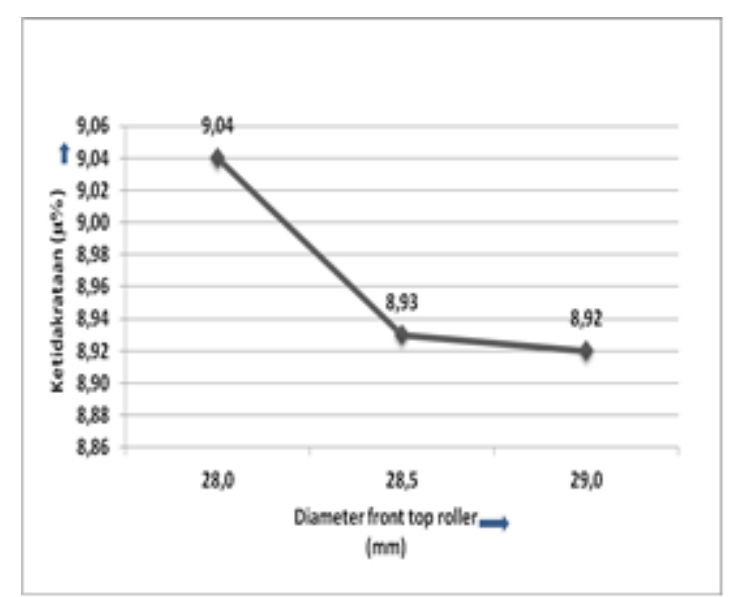

Gambar 3. Grafik Hubungan Diameter Front Top Roller dengan Ketidakrataan Benang.
Dari grafik diatas terlihat bahwa diameter front top roller makin tinggi ketidakrataan benang semakin rendah (kerataan benangnya semakin bagus). Hal ini disebabkan pada diameter top roller $29,0 \mathrm{~mm}$ (diameter front top roller semakin tinggi) titik jepit serat pada saat proses drafting semakin luas/semakin baik. Sehingga menyebabkan nilai ketidakrataan benangnya semakin rendah (benang semakin bagus).

\section{Kesimpulan}

Dari hasil percobaan variasi tekanan front top roller dengan variasi diameter yang dikombinasikan langsung di mesin ring spinning terhadap nilai ketidakrataan benang acrylic 100 $\%$ dapat disimpulkan sebagai berikut:

1. Tekanan front top roller berpengaruh signifikan terhadap nilai ketidakrataan benang acrylic $100 \%$. Variasi tekanan front top roller yang terbaik adalah $10 \mathrm{daN}$ dengan nilai ketidakrataan benang (U \%) sebesar 8,83 .

2. Diameter front top roller berpengaruh signifikan terhadap nilai ketidakrataan benang acrylic 100\%. Variasi diameter front top roller yang terbaik adalah 29,0 $\mathrm{mm}$ dengan nilai ketidakrataan benang ( $\mathrm{U}$ $\%$ ) sebesar 8,92.

3. Tidak ada interaksi antara tekanan dan diameter front top roller terhadap ketidakrataan benang. Kombinasi perlakuan yang terbaik adalah kombinasi antara tekanan front top roller 10 daN dengan diameter front top roller $29,0 \mathrm{~mm}$ dengan menghasilkan nilai ketidakrataan benang yang terendah/paling baik yaitu sebesar 8,78 .

\section{Daftar Pustaka}

Marjoere A Taylor, M. A. (1990). Technology Of Teextile Properties : London, Forbes Publication

Pawitro dkk., (1975). Teknologi Pemintalan Bagian Kedua: ITT Bandung

Peter Chang M.K. (2003). Pengendali Mutu Terpadu Untuk Industri Tekstil dan Konveksi Jakarta: Penerbit Pradnya Paramita,

Saleh, S. (1988). Statistik Induktip. Yogyakarta: Penerbit Liberty

Salura. (1977). Teori Draft dan Ketidakrataan benang: ITT Bandung 
Sugiarto N., \& Shigeru Watanabe. (1993). Teknologi Tekstil : Penerbit Pradnya Paramita, Jakarta

Wibowo, M. (1974). Evaluasi Tekstil Bagian Fisika : ITT Bandung.

W-Klien. (1983). A Pratical Guide to Ring Spinning, Short staple fiber series : Volume 4

Zinser. (1995). Hand Manual Book For Ring frame Machine : Zinser Germany 